\title{
Health Canada named in class action lawsuit
}

Previously published at www.cmaj.ca

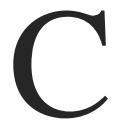
lass-action lawsuits against the company that manufactures the type 2 diabetes drug rosiglitazone (Avandia ${ }^{\circledR}$ ) also name the federal government, accusing Health Canada of failing to protect the public from the medication's "serious adverse medical events."

The lawsuits, which the Merchant Law Group filed in Ontario, Manitoba, Saskatchewan, Alberta, British Columbia, and Newfoundland and Labrador, claim that GlaxoSmithKline Inc. (GSK) failed to fully inform those who took rosiglitazone that they faced an increased risk of serious medical events, such as heart attacks and heart failure, according to a statement of claim filed in the Ontario Superior Court of Justice.

The lawsuit also alleges that GSK "did shoddy pre- and post-marketing research and testing on Avandia mainly for the purpose of obtaining financial benefit and ignoring the potentially serious risks posed to the public."

In addition, the class-action suit says that Health Canada "knew, or ought to have known, that there was a significant risk that Avandia was not properly or thoroughly tested by GSK, and that Avandia was a dangerous product."

None of these claims have been proven in court. The cases have not yet been certified as a class, meaning none of the courts has decided whether all of the defendants have enough in common to allow cases to proceed.

Health Canada would not comment upon the lawsuits at this time "because the matter is before the courts," said a spokesperson in an email to CMAJ.

The Canadian lawsuits follow a spate of claims in the United States against GSK regarding rosiglitazone and its potential links to myocardial infarction and ischemia. The pharmaceutical company has begun to offer settlements in some of those cases.

In an email, a spokesperson for GSK said the company could not comment on class-action settlements or other matters before the courts.

So far, GSK has not offered to settle the cases in Canada, says Tony Merchant, senior counsel at The Merchant Law Group. To date, about 500 people have contacted the firm regarding the suit, including the families of about 50 people who died and had been taking the medication.

Naming Health Canada in the lawsuit is intended to provoke changes in public policy around the way drugs are regulated, says Merchant. "Drug companies simply paying to have the problem go away isn't accomplishing the societal effect that is desirable, which is an increased safety approach. Instead, what it's doing is just meaning that they price into a drug the cost of paying for things going wrong."

In 2007, the US Food and Drug Administration (FDA) issued a safety alert about the possible association between rosiglitazone and an increased risk of heart problems. In the wake of subsequent studies that compared rosiglitazone to pioglitazone which suggested a higher risk of heart failure and death in patients taking rosiglitazone, the FDA is holding a public hearing this July into rosiglitazone. The agency will present updated evidence regarding the drug and its cardiac safety profile, and a current risk-benefit analysis of using the drug.

Health Canada followed the FDA warning with a "Dear Doctor" letter in November 2007 telling physicians not to prescribe rosiglitazone alone or to patients taking insulin, and advising against other combinations of medications with the drug. Health Canada posted a similar letter to patients taking rosiglitazone on its website. Both letters also cautioned against the use of rosiglitazone in patients with underlying heart disease or those who had previously experienced heart failure.

But Merchant and his clients believe those warnings were inadequate. If they are successful in securing a judgment against Health Canada, Merchant believes it will result in improvements to the drug regulatory system.

One of those clients, Debbie Allison, wants something more specific than regulatory change. In fact, she

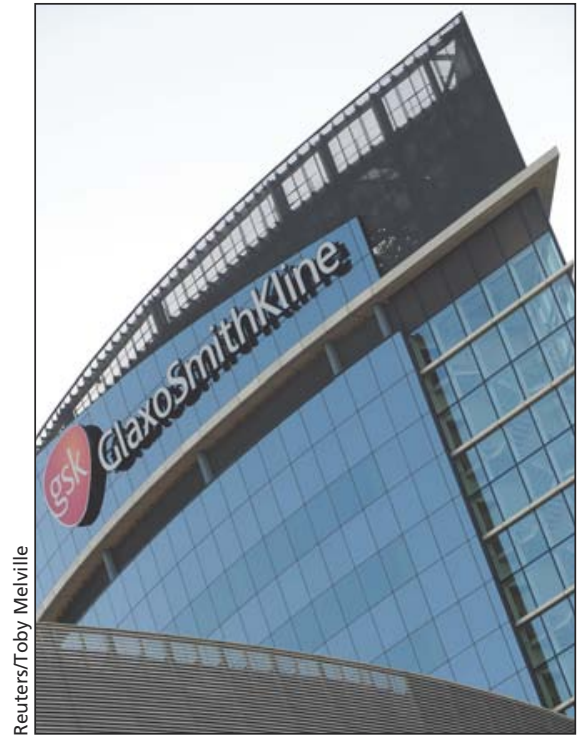

GlaxoSmithKline, whose logo is depicted here on the outside of one of its buildings in London, England, experienced a slump in sales of its diabetes drug rosiglitazone after it was linked to heart attack risk.

wants Health Canada to take rosiglitazone off the market.

Allison's husband, Jeff Lesmeister, was 43 years old when he dropped dead in 2007 from a sudden cardiac event, about eight days after being hospitalized for atrial fibrillation and having stents implanted. Lesmeister had been taking rosiglitazone to help manage his diabetes and had no previous history of heart disease or cardiac problems, she says, adding that a doctor had increased his dosage of rosiglitazone shortly before his death.

Allison says neither she nor her husband were aware of the Health Canada warnings. She believes Health Canada should recall rosiglitazone, and she is urging physicians not to prescribe it.

"I want the drug off the market," she says. "I joined the class action because it is public and people will be aware of it. A settlement means nothing to me. All the money in the world is not going to bring back what I lost."

"I lost my life partner," she adds. "I lost my life." — Laura Eggertson, Ottawa, Ont.

DOI:10.1503/cmaj.109-3283 